\title{
Research Square \\ Numerical analysis and mechanic theoretical derivations for optimizing the V-thread profiles in dental implant system
}

Yongqing Cai ( $\square$ caiyongqing33@126.com )

Hainan University

Research

Keywords: Dental implant, V-thread, biomechanics, theoretical derivation, finite element analysis

Posted Date: June 17th, 2021

DOl: https://doi.org/10.21203/rs.3.rs-591698/v1

License: (1) (1) This work is licensed under a Creative Commons Attribution 4.0 International License.

Read Full License 


\section{Title Page}

Title:

Numerical analysis and mechanic theoretical derivations for optimizing the V-thread profiles in dental implant system

Author names:

Yongqing Cai

Author's institutional affiliation:

Department of Mechanical and Electrical Engineering, Hainan University, Haikou, China.

Corresponding author:

Yongqing Cai

Address: \#58 People Avenue, Meilan District, Haikou City, Hainan Province, China.

E-mail: caiyongqing33@126.com

Tel: +8618389568003 


\begin{abstract}
Background: The thread design of the dental implant is an important feature to be considered in the optimization of the dental implant structure. The present study aimed to investigate the effects of V-thread profile design dimensions, including depth, width, pitch, thread helix angle and triangle thread apex angle on the mechanical characteristics of the bone-implant interface. A total of $588 \mathrm{~V}$-thread implant system models were constructed to investigate the effects of the dimension parameters on the stress distribution generated around the bone-implant interface under vertical occlusal force. Furthermore, the force transfer at the bone-implant interface was analyzed theoretically to analyze the force transmission mechanism at bone-implant for an optimized V-thread profile in the implants.
\end{abstract}

Results: The optimum thread pitch ranged from $1.0 \mathrm{~mm}$ to $1.2 \mathrm{~mm}$, when the triangle thread depth and width was $0.1 \mathrm{~mm}$. The theoretically derived results showed that, with the same implant diameter, when the thread depth was $0.1 \mathrm{~mm}$ and the thread pitch was $0.9 \mathrm{~mm}$, the optimal thread width was found to be $0.1026 \mathrm{~mm}$. This derived result was consistent with the simulation analysis results.

Conclusions: To design the optimal V-shape threads, the implant and thread dimensions, such as the implant diameter, thread pitch, thread width, thread helix angle and triangle thread apex angle should be comprehensively considered. The optimal designed thread in this study can dissipate the chewing load, as a result of the appropriate ratio of tensile force and shear force on bone-implant interface. The optimum designed thread profile can take full advantage of the carrying capacity of the tensile and shear of the bone, thereby bearing a high chewing load.

Keywords: Dental implant; V-thread; biomechanics; theoretical derivation; finite element analysis

\title{
Background
}

Dental rehabilitation with implants plays a pivotal role in the substitution of the lost teeth to regain the masticatory function in conditions of dental caries, periodontal disease or injury. Since their introduction in the 1970's [1,2], they still continue to remain popular, primarily due to their excellent and reliable long-term functional and aesthetic results. So far, dental implants have showed a successful track record in the long-term clinical applications, with a success rate as high as $90 \%$, if they are properly designed, manufactured, and inserted $[3,4]$. Despite the high success rates, the implant failure, marginal bone loss, and patient discomfort still sometimes occurs unexpectedly [5].

The critical function of the dental implants is to transfer the bite force to the bone on the boneimplant interface, similar to that of the natural intact teeth [6]. Due to the lack of the periodontal ligament, a direct connection is formed between the bone and the implant, and the bite force is 
transferred directly to the surrounding bones by the bone-implant interface. The key factor to determine the success or failure of the implant lies solely on the fact, whether the implant can support the bite force for a long time and safely transfer it to the surrounding bone [7]. Therefore, it is necessary to study the relationship between the implant characteristics and the load transferred, and the stress distribution at the bone-implant interface. Many researchers focused on maximizing the area of contact and minimizing the stress at the bone-implant interface to reduce the bone absorption [8]. In order to improve the stress distribution at the bone-implant interface, different types of implants were designed. The thread design of the dental implant is an important feature to be considered in the optimization of the dental implant structure.

The thread is used to maximize the contact area, improve the stability, and expand the surface area of the implant, conducive to the dissipation of the interfacial stress [9]. Therefore threaded implants are generally preferred over the smooth cylindrical implants to increase the contact area and improve implant stability [10].

The implant thread profile plays a vital role in enhancing the biomechanical effectiveness of implants [11]. The thread design should ideally maximize the initial contact, improve the initial stability, and create a better distribution of stress [12]. Among the commonly used thread profiles, such as the V-thread, square thread, buttress thread and reverse buttress thread, the V-thread has a stronger effect on the jawbone cutting in the procedure of insertion of the implant. V-thread design parameters needed to define the thread profile including the thread depth, thread width, thread pitch, thread helix angle and triangle thread apex angle. Varying these parameter dimensions affects the functional thread surface, thereby influencing the biomechanical characteristics at the bone-implant interface [13]. Understanding the influence of these thread parameters on the biomechanical effectiveness of the dental implants and applying them appropriately in the field of the implant science can improve the success rate of the implant. Therefore, it is important to investigate the relationship between the thread design and the bone-implant interface biomechanical characteristics.

Finite element analysis (FEA) allows the investigation of the relative merits of the different thread parameter dimensions and offers an insight into the stress distribution at the bone-implant interface [14]. Therefore, FEA was employed in this study to investigate the stress distribution at the bone-implant interface of the various V-threads and to find an optimal V-thread for the implant system. Subsequently, a theoretical derivation was performed to reveal the biomechanical characteristics on the bone-implant interface to confirm and verify the simulation results, and moreover give an optimum thread design.

\section{Results}

The displacement magnitudes in the implant and the cortical bone were much lower than the suggested threshold value of $0.15 \mathrm{~mm}$ [15]. Therefore, the stresses patterns and the magnitude of 
the maximum stress of implants and cortical bone were the main analyzing parameters.

\section{Stress Analysis}

The stress distribution patterns in the implant and the cortical bone were similar in all cases. Therefore, only the distribution trends in case with the V-thread of $0.1 \mathrm{~mm}$ depth, $0.1 \mathrm{~mm}$ width, and $0.9 \mathrm{~mm}$ pitch are shown in the present study.

When both the thread depth and width were $0.1 \mathrm{~mm}$, the minimum peak von Mises stress in the implant and cortical bone were found in cases of the thread pitch of $0.8 \mathrm{~mm}$ and $1.1 \mathrm{~mm}$ respectively. Therefore, when considering the maximum von Mises stress in the implant and the cortical bone at different thread depth and width, the thread pitch was designed as $0.9 \mathrm{~mm}$.

\section{Implant}

Fig. 4 shows the maximum von Mises stress in the implant. It can be seen that stress concentrated at the first thread of implant and at the thread tips of the implant in the neck region near the cortical bone. Table 2 shows the highest von Mises stress of the implant in $0.9 \mathrm{~mm}$ thread pitch with different thread depth and width. Table 3 shows the change in the magnitude of the maximum stress in the implant and cortical bone with different thread pitch values, when the thread depth and width were $0.1 \mathrm{~mm}$.

\section{Cortical bone}

The patterns of the maximum von Mises stress distribution for cortical bone are shown in Fig. 5. The figures show that the stress concentration appeared at the cortical bone around the implant neck, which potentially contributed to the marginal bone loss. Additionally, the peak stress magnitude was located at the bone that enclosed the first thread of implant on the upper surface of the cortical bone. Table 4 lists the maximum von Mises stress of cortical bone. All the stress values were found to be significantly lower than the yield of $100 \mathrm{MPa}$ for the cortical bone. Table 3 shows that the minimum peak cortical bone von Mises stress was observed at the thread pitch of $1.1 \mathrm{~mm}$.

\section{Discussion}

As previously mentioned, all cases had similar stresses distribution. Therefore, the optimum V-thread profile was determined by the maximum stress.

\section{Stress}

\section{Implant}

In Table 2, the peak stress magnitude was 198.0 MPa, which was much lower than the yield strength of the Ti alloy $(650 \mathrm{MPa})$. This indicates that all implants were safe and did not undergo a 
fracture or failure.

The minimum average stress values were found at $0.1 \mathrm{~mm}$ or $0.2 \mathrm{~mm}$ thread depth and $0.5 \mathrm{~mm}$ or $0.6 \mathrm{~mm}$ thread width. Therefore, it can be inferred that a lower thread depth $(0.1$ and $0.2 \mathrm{~mm})$ and appropriate thread width $(0.5$ and $0.6 \mathrm{~mm})$ reduced the implant stress. In Table 3 , when both the thread depth and width were $0.1 \mathrm{~mm}$, the minimum stress was observed at a thread pitch of 0.8 $\mathrm{mm}$.

The response of the bone in terms of resorption or healing is directly related to the stress within the bone, in accordance with Wolff's theory $[16,17]$. Therefore, the stresses in bone are the analysis parameters of great significance.

\section{Cortical bone}

The analysis of stress distribution suggests that the significant stress concentrations were located at the crestal of the cortical bone around the implant neck, and bone loss usually began at this crestal area [18].

From the viewpoint of mechanics, the concentration of the stress depends on the material property, the mutant shape, and the mutant dimension (the cutting shape and dimension of the bone for the insertion of the implant with thread). Under the same structural mutation, the material elastic modulus is directly proportional to the stress concentration. The cortical bone has a larger elastic modulus than the cancellous bone, thus the cortical bone exhibited a severe stress concentration than the cancellous bone with the same implant thread profile. Therefore, the biomechanics of only the cotical bone were investigated in this study.

From Table 4, the minimum average peak von Mises stress of cortical bone was found to be 27.73 $\mathrm{MPa}$ and $21.76 \mathrm{MPa}$, when thread depth was $0.1 \mathrm{~mm}$ and thread width was $0.1 \mathrm{~mm}$, respectively. Based on the results, the threads with small dimensions of depth $(0.1 \mathrm{~mm})$ and width $(0.1 \mathrm{~mm})$ were suggested for the use in the model in the neck area of implant, because these microthreads helped to reduce the stress values in cortical bone crest. This could slow down the bone resorption, compared with the other coarse threads with large thread depth and width. The microthreads reduced the stress concentration in the cortical bone.

Table 3 shows that the minimum peak von Mises stress for the triangle thread with $0.1 \mathrm{~mm}$ depth and $0.1 \mathrm{~mm}$ width was $17.02 \mathrm{MPa}$, at a thread pitch of $1.1 \mathrm{~mm}$. Therefore, the optimum thread pitch for V-thread with $0.1 \mathrm{~mm}$ depth and $0.1 \mathrm{~mm}$ was $1.1 \mathrm{~mm}$.

Considering the stress magnitude and distribution, the V-thread with $0.1 \mathrm{~mm}$ of thread depth, 0.1 $\mathrm{mm}$ of thread width, and $1.1 \mathrm{~mm}$ of thread pitch were thought to be the optimal V-thread for a better stresses distribution at the cortical bone and improving the stability of the implant system.

\section{Theoretical analysis}


In the present study, a complete osseo-integration condition was assumed at the implant-bone interface, and the forces acting on bone and implant were the action and reaction forces. Therefore, only the force system acting in implant was analyzed, and the force system acting on bone had an equal magnitude and opposite direction.

As shown in Fig. 6, the implant was subjected to the uniform axial chewing load (vertical direction). Assuming that the load was uniformly transmitted on the thread bone interface as shown in Fig. 6, the distribution load $F$ on thread surface was analyzed for its action on the V-thread.

Firstly, the direction of the transmitted load $F$ was same as the applied vertical chewing load. To analyze the thread helix angle effects on the converting of $F$, the local part A was considered as the research object and it was amplified, as A shown in Fig. 6.

The vertical load $F$ can be resolved as $F_{\mathrm{N}}$ - the force normal to the thread helix line and $F_{\tau \alpha}$ - the shear force tangent to the thread helix line.

$$
F_{N}=F \bullet \cos \alpha,
$$

$$
F_{\tau \alpha}=F \bullet \sin \alpha
$$

where, $\alpha$ is the thread helix angle.

and $\tan \alpha=\frac{p}{\pi D}$

or $\alpha=\arctan \left(\frac{p}{\pi D}\right)$

where, $p$ is the thread pitch, $D$ is the implant diameter.

The cross section of the triangle thread in the plane that contains the force $F_{\mathrm{NN}}$ and vertical to the thread helix line was taken as the second research object with amplification B shown in Fig. 6.

Here, the force $F_{\mathrm{N}}$ can be resolved as $F_{\mathrm{NN}}$ - the force normal to the thread inclined plane and $F_{N \tau \beta}$ the shear force tangent to the thread inclined plan.

$$
F_{N N}=F_{N} \bullet \cos \left(\frac{1}{2} \beta\right)=F \bullet \cos \alpha \bullet \cos \left(\frac{1}{2} \beta\right)
$$


$F_{N \tau \beta}=F_{N} \bullet \sin \left(\frac{1}{2} \beta\right)=F \bullet \cos \alpha \bullet \sin \left(\frac{1}{2} \beta\right)$

where, $\beta$ is the triangle thread apex angle.

Finally the vertical load $F$ was converted as one normal force of $F_{\mathrm{NN}}$, and the two shear forces $F_{\tau \alpha}$ and $F_{N \tau \beta}$. These two shear force collectively form the resultant shear force $F_{\tau}$ as shown in Fig. 6.

$$
\begin{aligned}
F_{\tau}=\sqrt{F_{\tau \alpha}^{2}+F_{N \tau \beta}^{2}} & =\sqrt{F^{2} \sin ^{2} \alpha+F^{2} \cos ^{2} \alpha \bullet \sin ^{2}\left(\frac{1}{2} \beta\right)} \\
& =F \sqrt{\sin ^{2} \alpha+\cos ^{2} \alpha \bullet \sin ^{2}\left(\frac{1}{2} \beta\right)}
\end{aligned}
$$

According to previous studies, the cortical bone yield compressive strength $\left[\sigma_{\mathrm{c}}\right]$, tensile strength $\left[\sigma_{\mathrm{t}}\right]$, and shear strength $\left[\tau_{\mathrm{s}}\right]$ for cortical bone were 179.1 MPa, 121.3 MPa, and 64.3 MPa, respectively [19]. The compressive stress and tensile stress were introduced by the normal force. However, the bone can resist a higher stress value for the compression than the tensile stress. Therefore, the tensile strength and shear strength were taken into account in this study.

To design an optimum V-thread profile, the ratio of converted normal force and shear force should be equal to the ratio of the tensile strength and the shear strength, in order to give full play to the loading capacity of the bone as shown by the following equation:

$$
\frac{F_{N N}}{F_{\tau}}=\frac{F \bullet \cos \alpha \bullet \cos \left(\frac{1}{2} \beta\right)}{F \sqrt{\sin ^{2} \alpha+\cos ^{2} \alpha \bullet \sin ^{2}\left(\frac{1}{2} \beta\right)}}=\frac{\cos \alpha \bullet \cos \left(\frac{1}{2} \beta\right)}{\sqrt{\sin ^{2} \alpha+\cos ^{2} \alpha \bullet \sin ^{2}\left(\frac{1}{2} \beta\right)}}=\frac{\left[\sigma_{\mathrm{t}}\right]}{\left[\tau_{\mathrm{s}}\right]}
$$

For $\sin ^{2} \alpha+\cos ^{2} \alpha=1$, and $\sin ^{2}\left(\frac{1}{2} \beta\right)+\cos ^{2}\left(\frac{1}{2} \beta\right)=1$ the above equation can be deformed as 


$$
\begin{aligned}
\frac{F_{N N}}{F_{\tau}} & =\frac{\cos \alpha \bullet \cos \left(\frac{1}{2} \beta\right)}{\sqrt{1-\cos ^{2} \alpha+\cos ^{2} \alpha \bullet \sin ^{2}\left(\frac{1}{2} \beta\right)}}=\frac{\cos \alpha \bullet \cos \left(\frac{1}{2} \beta\right)}{\sqrt{1-\cos ^{2} \alpha\left[1-\sin ^{2}\left(\frac{1}{2} \beta\right)\right]}} \\
& =\frac{\cos \alpha \bullet \cos \left(\frac{1}{2} \beta\right)}{\sqrt{1-\cos ^{2} \alpha \bullet \cos ^{2}\left(\frac{1}{2} \beta\right)}}=\frac{\left[\sigma_{\mathrm{t}}\right]}{\left[\tau_{\mathrm{s}}\right]}
\end{aligned}
$$

To solve the above equation, $\cos \alpha \bullet \cos \left(\frac{1}{2} \beta\right)$ was set as $x$, then we obtain:

$$
\begin{aligned}
& \frac{x}{\sqrt{1-x^{2}}}=\frac{\left[\sigma_{\mathrm{t}}\right]}{\left[\tau_{\mathrm{s}}\right]} \\
& x=\cos \alpha \bullet \cos \left(\frac{1}{2} \beta\right)
\end{aligned}
$$

For cortical bone, the Equation (8) can be deformed as

$\frac{x}{\sqrt{1-x^{2}}}=\frac{\left[\sigma_{\mathrm{t}}\right]}{\left[\tau_{\mathrm{s}}\right]}=\frac{121.3}{64.3}=1.89$

and on solving Equation (12) we obtain Equation (13):

$$
x=\cos \alpha \cdot \cos \left(\frac{1}{2} \beta\right)=0.8837
$$

When the thread pitch was considered as $1.1 \mathrm{~mm}$, and the implant diameter in this study was D $=0.3 \mathrm{~mm}$. According to Equation (4) the thread helix angle can be obtained as follows:

$\alpha=\arctan \left(\frac{p}{\pi D}\right)=\arctan \left(\frac{1.1}{3.14 \times 3.0}\right)=6.660^{\circ}$

Combining Equation (13) and Equation (14), we can obtain the triangle thread apex angle as $\beta=54.32^{\circ}$ 
From the above discussion about the simulation result, the optimum thread depth was considered to be $0.1 \mathrm{~mm}$ in this study, and then the optimum thread width dimension was calculated.

According to the amplification of the triangle cross section scenario $\mathrm{B}$, the follow trigonometric relation can be easily obtained:

$\beta=2 \times \arctan \left(\frac{h}{2 t}\right)$

or $h=\tan \left(\frac{1}{2} \beta\right) \times 2 \times t$

where, $t$ is the thread depth, and $h$ is the thread width.

When the triangle thread apex angle $\beta=54.32^{\circ}$, and the thread depth $t=0.1 \mathrm{~mm}$, the optimum thread width $h=0.1026 \mathrm{~mm}$. The theoretical analysis optimum triangle thread dimension parameters were consistent with the simulation results.

The designed optimum thread dimensions in the present study can convert the chewing load into appropriate normal force and shear force, and improve the bone bearing capacity. In other words, using these designed optimum threads, the implant system, especially the bone can withstand greater chewing loads.

It is important to notice that the theoretical derivation process of the optimum thread design in the present study involved almost all the implant and thread dimension parameters, including the implant diameter, thread pitch, thread helix angle, thread depth, thread width and the V-thread apex angle. This indicates that all these parameters should be considered comprehensively to improve the bearing capacity of the implant system.

\section{Conclusions}

To design the optimal V-shape threads, the implant and thread dimensions, such as the implant diameter, thread pitch, thread width, thread helix angle, and triangle thread apex angle need to be comprehensive considered. The optimal designed thread in this study can dissipate the chewing load as the appropriate ratio of tensile force and shear force at the bone-implant interface. The optimum designed thread profiles appropriated a full advantage of the carrying capacity of the tensile and shear of the bone, and thus the implant system supported a higher chewing load.

\section{Methods}


The three-dimensional geometrical model of the cortical bone, cancellous bone and dental implants with various V-threads was established using the Computer-Aided Design (CAD) software SolidWorks 2017 (Dassault Systèmes SolidWorks Corporation, MA, USA).

\section{CAD Modeling}

\section{Bone Model}

The present study employed simplified bone geometry, in order to perform a comparative study. The simplified jawbone was approximately $10 \mathrm{~mm}$ in width bucco-lingually, $21 \mathrm{~mm}$ in width corono-apically, and $15 \mathrm{~mm}$ in length mesiodistally [20] (Fig. 1). A core of cancellous bone was covered with a thick layer of cortical bone with a constant width of $2 \mathrm{~mm}$ [21].

\section{Dental implant model}

Cylindrical thread implant models designed in this study have the same diameter and length, in order to focus solely on the effect of thread design. The diameter and length of the implant was set to be $3 \mathrm{~mm}$ and $6 \mathrm{~mm}$, respectively.

According to previous studies [22,23], the implant and the abutment was considered to be an integrated part of the dental implant in this study. The outcome was not affected by this simplification, as the stress induced on the implant-bone was of major importance and that induced on the implant itself was not important. The detailed geometry of the dental implant is shown in Fig. 2.

Different V-thread profiles were considered in this study, and the geometry of the V-thread was defined by the following parameters: thread width, thread depth, thread pitch, thread helix angle and thread apex angle. In this study, the thread width, thread depth and thread pitch were set as input variables as shown in Fig. 2. The variations in the thread width and thread depth were set in the range of 0.1-0.7 mm, and the thread pitch was set 0.5-1.6 mm. The corresponding thread helix angle, thread apex angle was calculated based on the known thread width, thread depth, and thread pitch.

\section{Finite Element Modeling}

All the constructed CAD models were imported to ABAQUS software for FEA. Ten-node tetrahedral element was used for designing the mesh in the bone and the implant [24]. The mesh implant system model is shown in Fig. 3(a). Each of the case models was composed of 149,661 nodes and 98,221 elements (Table 1) with a small difference in various cases.

\section{Material Properties}

The bone properties were considered to be linear elastic, homogeneous and isotropic from earlier 
studies $[25,26]$. The implant material was assumed to be Ti6Al4V [20]. The mechanical materials properties were shown in Table 1 [27-29].

\section{Loading and boundary conditions}

Fig. 3(b) shows the loading configuration and boundary conditions. The base of the jawbone was considered to be completely constrained in all directions. According to previous studies [30,31], a full osseo-integration condition was assumed, and the bone-implant interface was modeled in a tie constraint. The implant was rigidly connected to the surrounding bone by node-sharing, so that a sliding or separation in the bone-implant interface was not possible. A distributed force of $100 \mathrm{~N}$ was applied vertically on the top of the abutment, similar to the previously assumed in literature $[25,32]$.

\section{List of abbreviations}

FEA: Finite element analysis; CAD: Computer-Aided Design

\section{Ethics approval and consent to participate}

Not applicable.

\section{Consent for publication}

Not applicable.

\section{Availability of data and materials}

All data generated or analysed during this study are included in this published article.

\section{Competing interests}

The author declares no competing interests.

\section{Funding}

This work was supported by Hainan Provincial Natural Science Foundation of China (120MS003 and 118QN184) and Hainan University [KYQD(ZR)1835].

\section{Authors' contributions}

YC did all the research work for this study. The author read and approved the final manuscript.

\section{Acknowledgements}

Not applicable.

\section{Reference}


1. Adell R, Hansson BO, Brånemark PI, Breine U. Intraosseous anchorage of dental prostheses. Scand J Plast Reconstr Surg Hand Surg. 1970; 4: 19-34.

2. Papaspyridakos P, Mokti M, Chen CJ, Benic GI, Gallucci GO, Chronopoulos V. Implant and prosthodontic survival rates with implant fixed complete dental prostheses in the edentulous mandible after at least 5 years: a systematic review. Clin Implant Dent R. 2015; 16: 705-717.

3. Turkyilmaz I. Influence of bone density on implant stability parameters and implant success: a retrospective clinical study. BMC Oral Health. 2008; 8: 32.

4. Ostman PO, Hellman M, Sennerby L. Immediate occlusal loading of implants in the partially edentate mandible: a prospective 1-year radiographic and 4-year clinical study. Int J Oral Max Impl. 2008; 23: 315-322.

5. Expósito M, Hirsch J, Lekholm U, Thomsen P. Biological factors contributing to failures of osseointegrated oral implants, (I). Success criteria and epidemiology. Eur J Oral Sci. 1998; 106: $527-551$.

6. Abuhussein H, Pagni G, Rebaudi A, Wang HL. The effect of thread pattern upon implant osseointegration. Clin Oral Implan Res. 2010; 21: 129-136.

7. Brunski JB. Biomechanical factors affecting the bone-dental implant interface. Clin Mater. 1992; 10: 153-201.

8. Chun HJ, Cheong SY, Han JH, Heo SJ, Kim MH. Evaluation of design parameters of osseointegrated dental implants using finite element analysis. J Oral Rehabil. 2010; 29: 565-574.

9. Huang HL, Chang CH, Hsu JT, Fallgatter AM, Ko CC. Comparison of implant body designs and threaded designs of dental implants: a 3-dimensional finite element analysis. Int J Oral Max Impl. 2007; 22: 551-562.

10. Sykaras N, Iacopino AM, Marker VA, Triplett RG, Woody RD. Implant materials, designs, and surface topographies: their effect on osseointegration. a literature review. Int J Oral Max Impl. 2000; 15: 675-690.

11. Brunski JB. In vivo bone response to biomechanical loading at the bone/dental-implant interface. Adv Dent Res. 1999; 13: 99-119.

12. Ivanoff CJ, Gröndahl K, Sennerby L, Bergström C, Lekholm U. Influence of variations in implant diameters: a 3- to 5-year retrospective clinical report. Int J Oral Max Impl. 1999; 14: 173-180.

13. Misch CE. Dental Implant Prosthetics. USA, St Louis: Mosby Publishing; 2005. 
14. Hanssona S, Werke M. The implant thread as a retention element in cortical bone: the effect of thread size and thread profile: a finite element study. J Biomech. 2003; 36: 1247-1258.

15. Velmurugan D, Alphin MS. Micromotion of Immediately Loaded Zirconia Dental Implants for Various Parametric Conditions: A Three-Dimensional Finite Element Study. J Biomater Tiss Eng. 2018; 8: 962-971.

16. Brand RA. Biographical Sketch: Julius Wolff, 1836-1902. Clin Orthop Relat Res. 2010; 468: 1047-1049.

17. Mavi B, Antoli V. Optimal mechanical environment of the healing bone fracture/osteotomy. Int Orthop. 2012; 36: 689-695.

18. Flemming L. Loss of osseointegration caused by occlusal load of oral implants. A clinical and radiographic study in monkeys. Clin Oral Implants Res. 1996; 7: 143.

19. Reilly DT, Burstein AH. The elastic and ultimate properties of compact bone tissue. J Biomech. 1975; 8: 393

20. I-Chiang C, Lee SY, Jiang CP. Effects of implant neck design on primary stability and overload in a type IV mandibular bone. Int J Numer Meth Bio. 2015; 30: 1223-1237.

21. Ausiello P, Franciosa P, Martorelli M, Watts DC. Effects of thread features in osseo-integrated titanium implants using a statistics-based finite element method. Dent Mater. 2012; 28: 919-927.

22. Duraisamy V, Santha AM, Ar TBJ. The sensitivity of contact stresses in the mandibular premolar region to the shape of Zirconia dental implant: A 3D finite element study. Pol J Med Phys Eng. 2018; 24: 55-63.

23. Porrua AR, Rodríguez YP, Rodríguez LMS, Acosta OP, González JE. The effect of diameter, length and elastic modulus of a dental implant on stress and strain levels in peri-implant bone: A 3D finite element analysis. Bio-Med Mater Eng. 2020; 30: 541-558.

24. Liang R, Guo W, Qiao X, Wen H, Yu M, Tang W, Liu L, Wei Y, Tian W. Biomechanical analysis and comparison of 12 dental implant systems using 3D finite element study. Comput Method Biomec. 2015; 18: 1340-1348.

25. Shirazi HA, Ayatollahi MR, Asnafi A. To reduce the maximum stress and the stress shielding effect around a dental implant-bone interface using radial functionally graded biomaterials. Comput Method Biomec. 2017; 20: 1-10. 
26. Maryam G, Hamidreza K, Reza A, Mahdi K. Finite Element Analysis of Dental Implants with and without Microthreads under Static and Dynamic Loading. J Long Term Eff Med Implants. 2017; 27: 25 .

27. Kasani R, Attili BKRS, Dommeti VK, Merdji A, Biswas JK, Roy S. Stress distribution of overdenture using odd number implants-A Finite Element Study. J Mech Behav Biomed Mater. 2019; 98: 369-382.

28. Pirmoradian M, Naeeni HA, Firouzbakht M, Toghraie D, Khaje khabaz M, Darabi R. Finite element analysis and experimental evaluation on stress distribution and sensitivity of dental implants to assess optimum length and thread pitch. Comput Meth Prog Bio. 2020; 187: 105258.

29. Jung WK, Lee WS, Kwon HB. Effects of abutment screw preload in two implant connection systems: A 3D finite element study. J Prosthet Dent. 2019; 122: 474.e1- 474.e8.

30. Dhatrak P, Shirsat U, Sumanth S, Deshmukh V. Finite Element Analysis and Experimental Investigations on Stress Distribution of Dental Implants around Implant-Bone Interface. Mater Today: Proc. 2018; 5: 5641-5648.

31. Pérez-Pevida E, Aritza BV, Chávarri-Prado D, Jiménez-Garrudo A, Sánchez-Lasheras F, Solaberrieta-Méndez E, et al. Biomechanical consequences of the elastic properties of dental implant alloys on the supporting bone: finite element analysis. Biomed Res Int. 2016; 2016 : 1850401.

32. Pirjamalineisiani A, Sarafbidabad M, Jamshidi N, Esfahani FA. Finite element analysis of post dental implant fixation in drilled mandible sites. Comput Biol Med. 2017; 81: 159-166. 


\section{Figures}

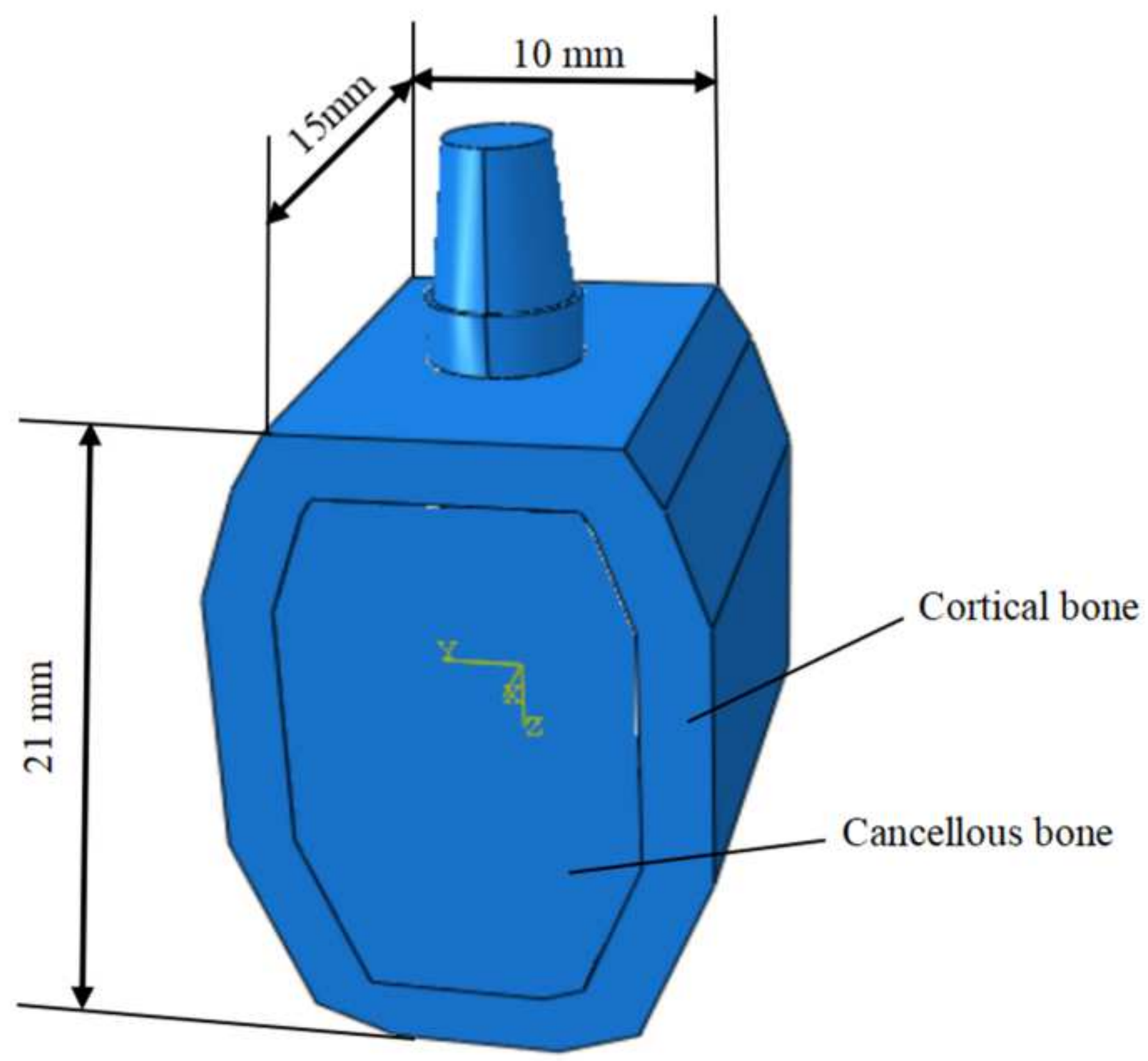

Figure 1

The present study employed simplified bone geometry, in order to perform a comparative study. The simplified jawbone was approximately $10 \mathrm{~mm}$ in width bucco-lingually, $21 \mathrm{~mm}$ in width corono-apically, and $15 \mathrm{~mm}$ in length mesiodistally 


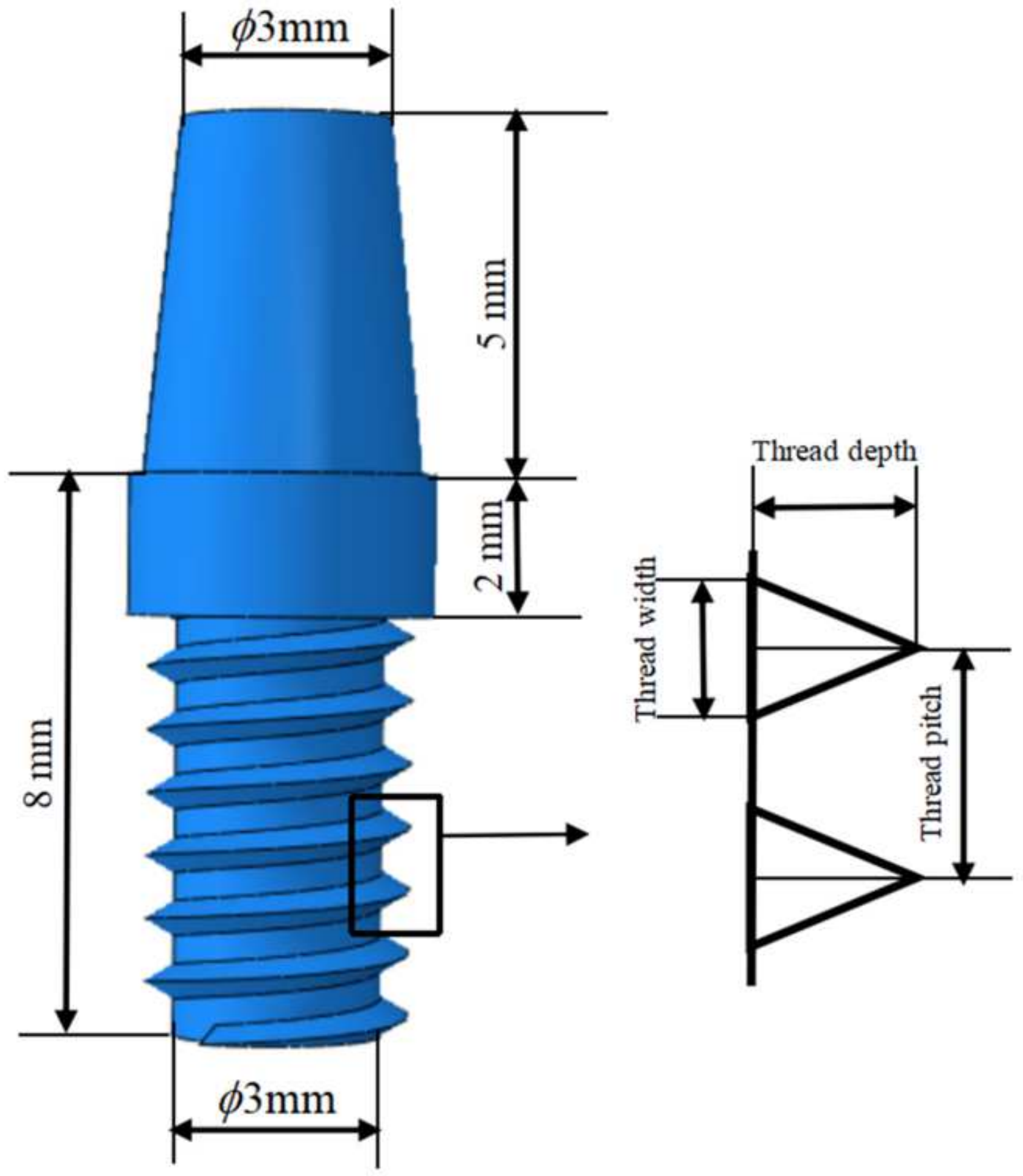

Figure 2

Different V-thread profiles were considered in this study, and the geometry of the V-thread was defined by the following parameters: thread width, thread depth, thread pitch, thread helix angle and thread apex angle. In this study, the thread width, thread depth and thread pitch were set as input variables as shown in Fig. 2 


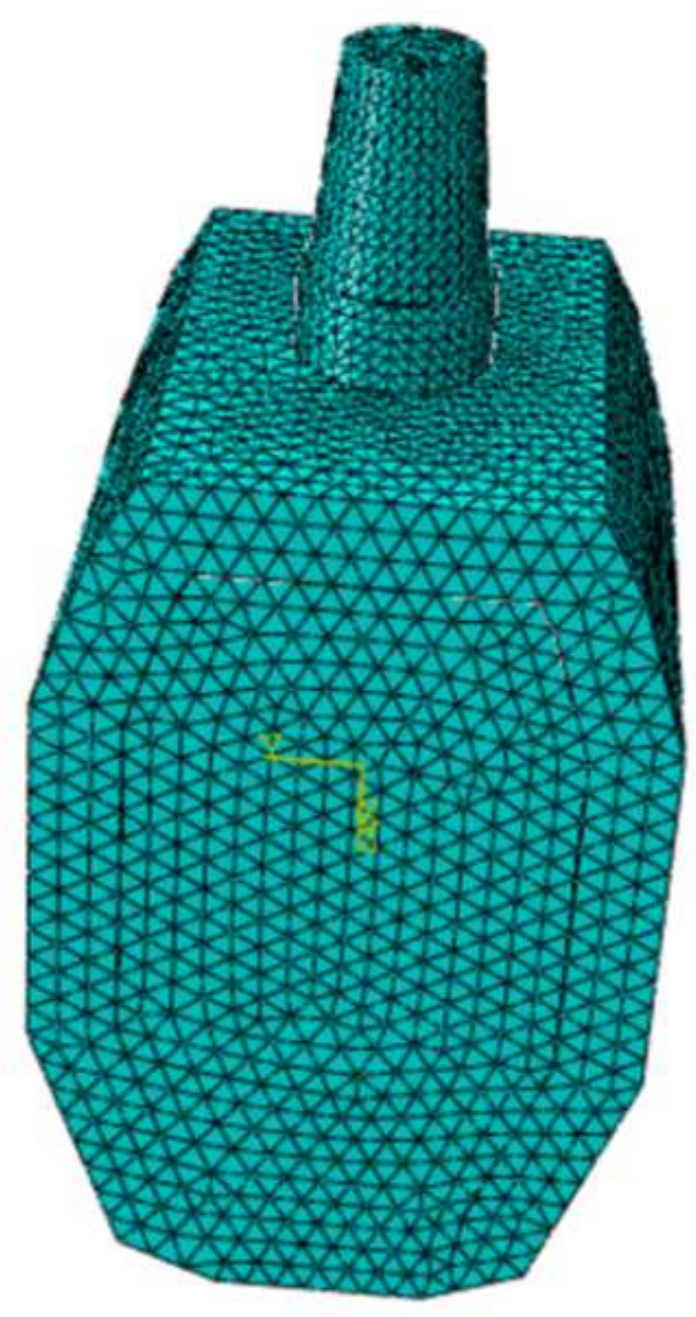

(a)

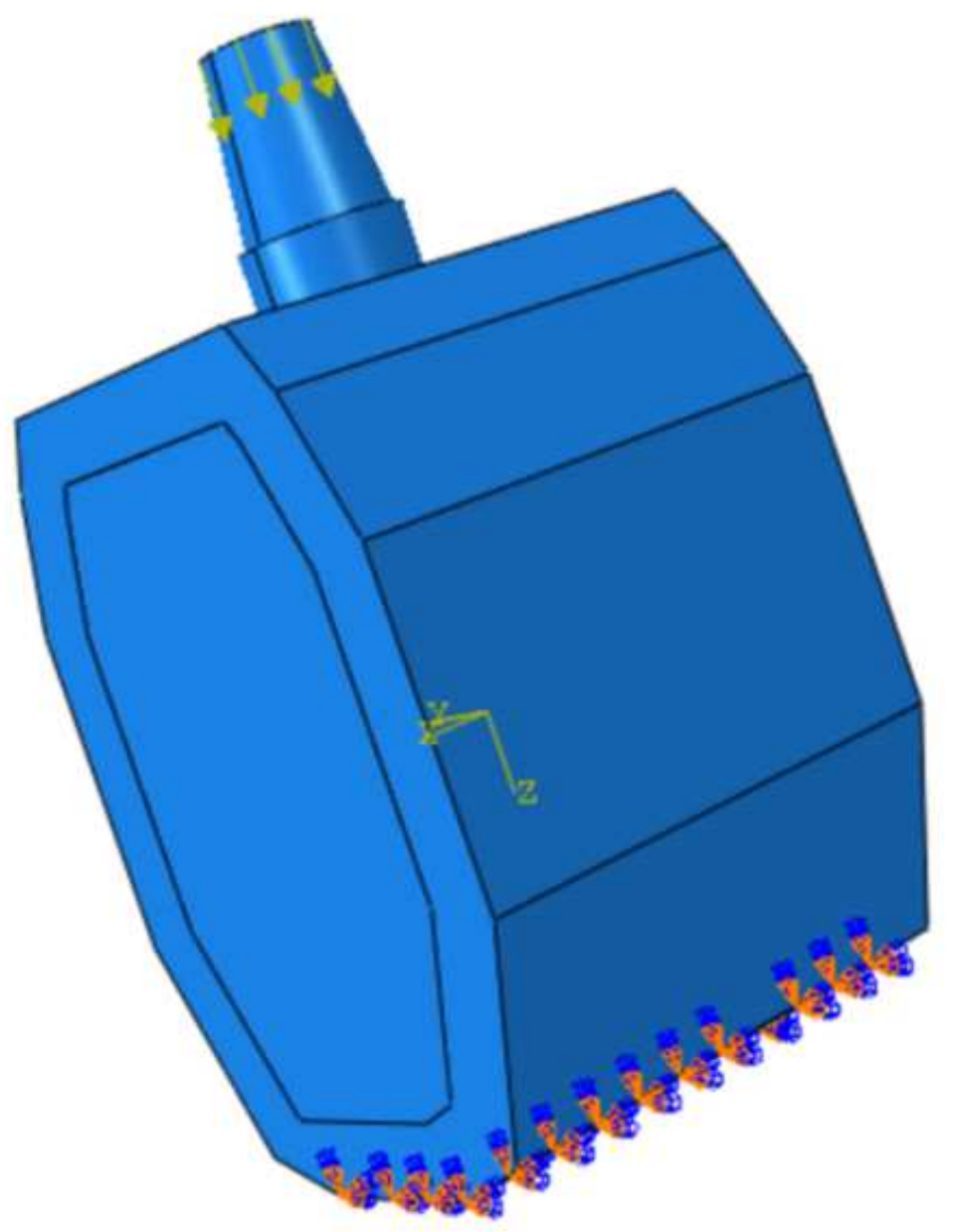

(b)

\section{Figure 3}

All the constructed CAD models were imported to ABAQUS software for FEA. Ten-node tetrahedral element was used for designing the mesh in the bone and the implant [24]. The mesh implant system model is shown in Fig. 3(a). Fig. 3(b) shows the loading configuration and boundary conditions. The base of the jawbone was considered to be completely constrained in all directions. According to previous studies [30, 31], a full osseo-integration condition was assumed, and the bone-implant interface was modeled in a tie constraint. 


\section{$\mathrm{S}$, Mises}

(Avg: 75\%)

\begin{tabular}{|r|r|}
\hline & $+1.042 \mathrm{e}+02$ \\
& $+9.557 \mathrm{e}+01$ \\
& $+8.693 \mathrm{e}+01$ \\
& $+7.830 \mathrm{e}+01$ \\
& $+6.966 \mathrm{e}+01$ \\
& $+6.102 \mathrm{e}+01$ \\
& $+5.238 \mathrm{e}+01$ \\
& $+4.374 \mathrm{e}+01$ \\
& $+3.510 \mathrm{e}+01$ \\
& $+2.646 \mathrm{e}+01$ \\
& $+2.782 \mathrm{e}+01$ \\
& +1.78 \\
$+9.185 \mathrm{e}+00$ \\
$+5.457 \mathrm{e}-01$
\end{tabular}

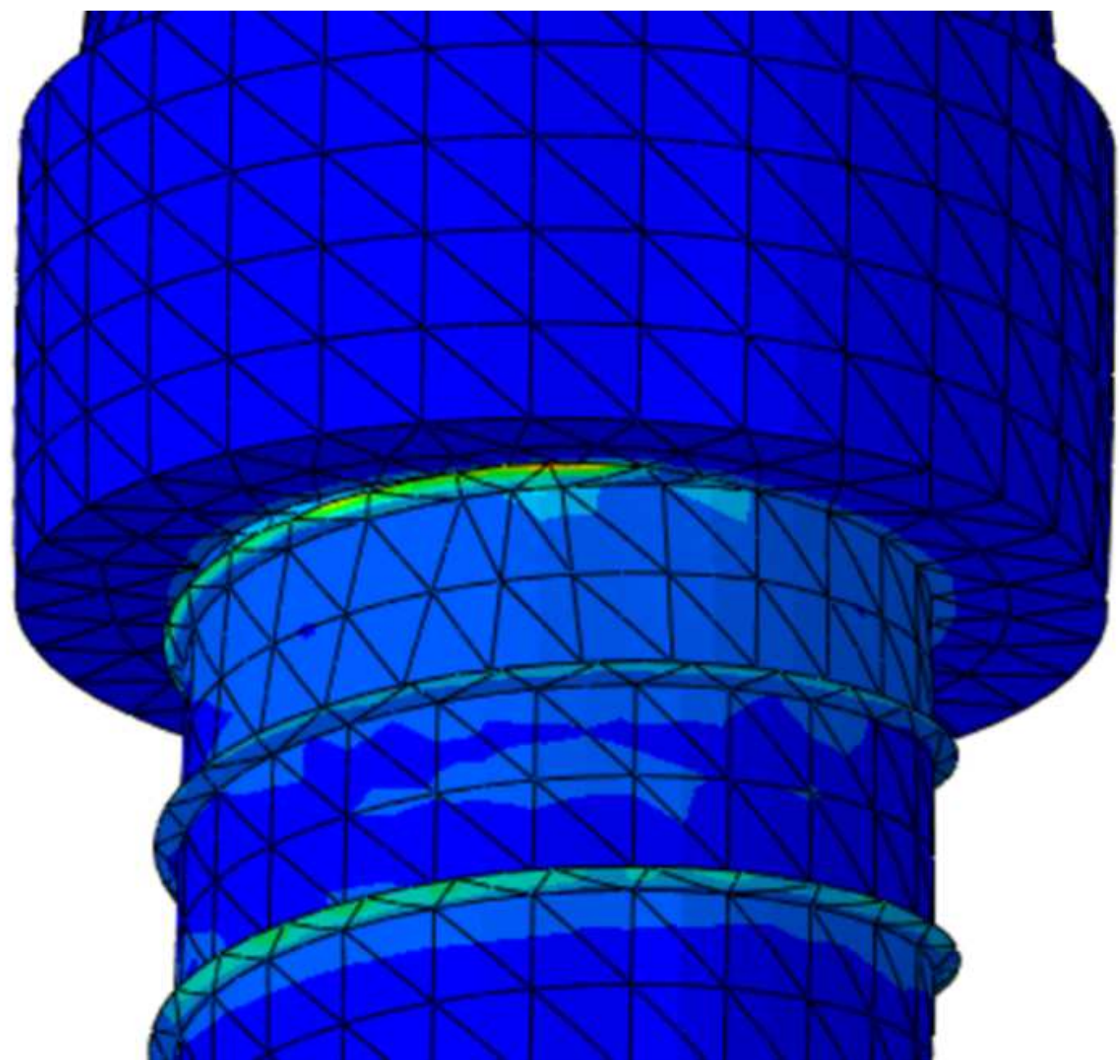

\section{Figure 4}

shows the maximum von Mises stress in the implant. It can be seen that stress concentrated at the first thread of implant and at the thread tips of the implant in the neck region near the cortical bone
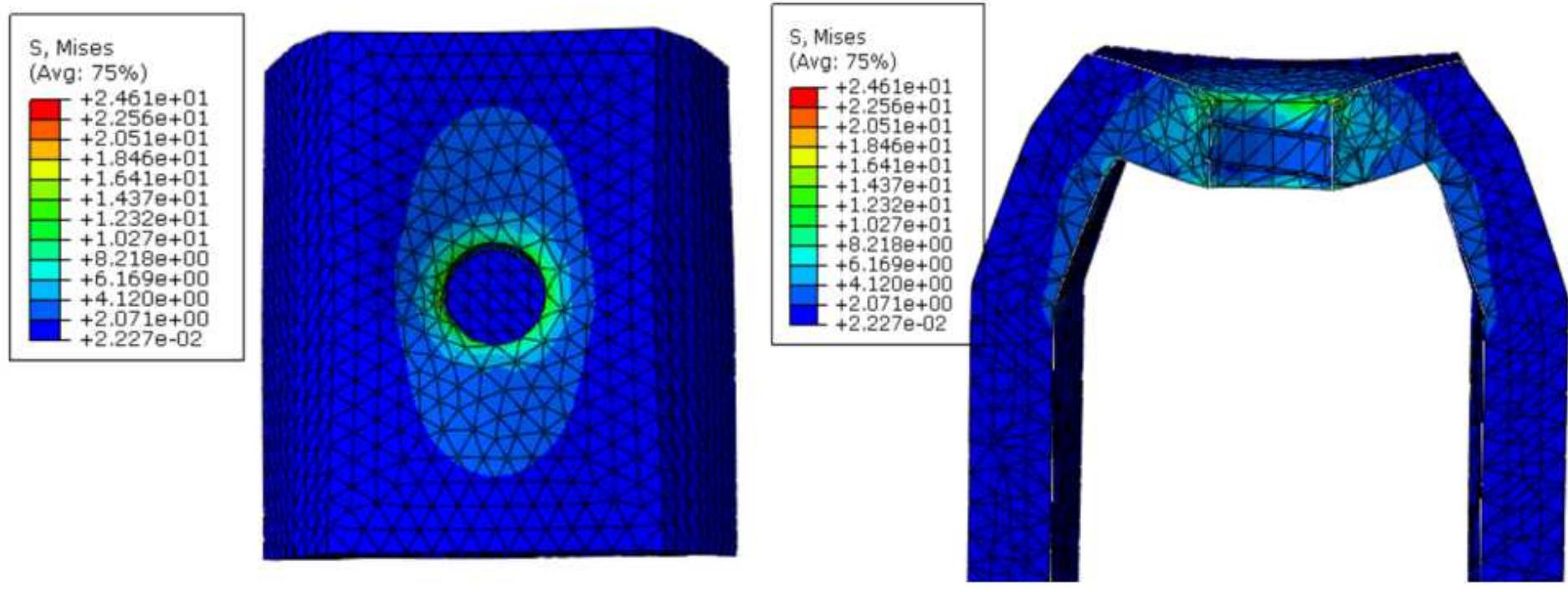

(a)

(b)

Figure 5 
The patterns of the maximum von Mises stress distribution for cortical bone are shown in Fig. 5

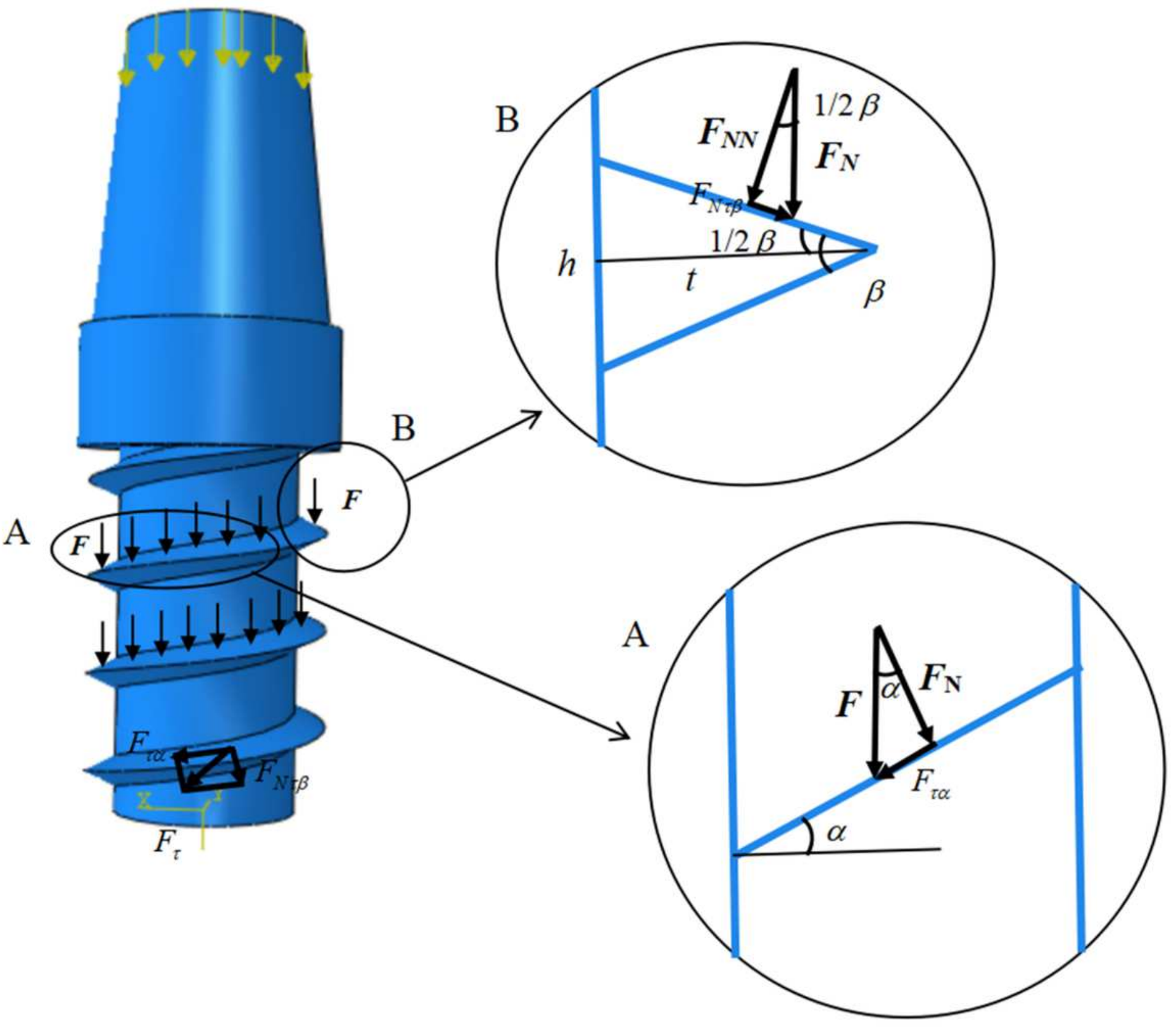

Figure 6

Firstly, the direction of the transmitted load $\mathrm{F}$ was same as the applied vertical chewing load. To analyze the thread helix angle effects on the converting of $F$, the local part $A$ was considered as the research object and it was amplified, as A shown in Fig. 6. 